\title{
"A CIDADE NÃO É AQUILO QUE SE VÊ DO PÃO DE AÇÚCAR": NARRATIVAS URBANAS EM RUBEM FONSECA
}

\author{
"La ville c'est pas ça que on voit du Pão de Açúcar": \\ récits urbaines dans Rubem Fonseca
}

Robert Moses Pechman (IPPUR/UFRJ)

\begin{abstract}
RESUMO: Rubem Fonseca dialoga com a tragédia em busca de alguma transcendência, para sempre perdida, no cotidiano das grandes cidades, onde a figura do herói não é mais possível, diante da crise contemporânea dos valores. Os personagens vivem numa sociedade em que ao eclipse da ordem do transcendente seguiu-se o eclipse da crença na razão.
\end{abstract}

PALAVRAS-CHAVE: Cidade; Literatura; Leitura; Confiança; Sociabilidade.

RÉSUMÉ: Rubem Fonseca dialogue avec la tragédie en cherchant quelque transcendence, pour toujour perduée, au cotidien des grandes villes, oú la figure du hero n'est pas plus possible, devant la crise contemporaine des valeurs. Des personages vivent dans une societé oú à l'eclipse de l'ordre du transcendente suive l'eclipse de la racionalité.

MOTS-CLÉ: Ville; Literature; Lecture; Confiance; Sociabilité. 


\section{“A CIDADE NÃO É AQUILO QUE SE VÊ DO PÃO DE AÇÚCAR":}

NARRATIVAS URBANAS EM RUBEM FONSECA

Simplício. Simplício é o personagem principal do romance A luneta mágica, escrito por Joaquim Manoel de Macedo em 1869. Simplício é completamente míope, física e moralmente. Além de nada enxergar que não fossem vultos, não consegue concatenar duas ideias e, por isso, não consegue fazer juízo do mundo em que vive.

Indo consultar um feiticeiro armênio, especialista em ótica, ganha de presente uma luneta, que é mágica, e que, utilizada em certas condições, permite que se veja além das aparências. Assim, de posse da capacidade de enxergar, Simplício passa a poder fazer juízo de seu meio. Começando por observar sua família e a vizinhança, Simplício vai ampliando o âmbito de sua visão à medida que começa a passear pela cidade. Como tudo o que Simplício queria era enxergar, a luneta mágica era um regalo dos céus, mas que iria lhe meter em inúmeras trapalhadas, pois, com a luneta, Simplício veria “ou todo o bem ou todo o mal" que existisse na sociedade, dependendo do tipo de lente que usasse. Assim, de posse da capacidade de enxergar, Simplício pode ler o mundo, a começar pela cidade do Rio de Janeiro, onde vive.

Achando-se curado de sua miopia moral, o personagem de Macedo experimenta as propriedades mágicas da luneta, sejam as lentes através das quais se divisa o bem em tudo o que elas pousam, sejam as lentes que só revelam o mal da sociedade, coisas que só lhe trazem infelicidade:

Pela visão do mal e pela visão do bem, pelo ódio ou pelo amor da humanidade, pelo mau juízo a respeito de todos ou pelo bom juízo a respeito de todos, as duas lunetas levaram-me ao mesmo perigo, ao mesmo fim, à mesma calamidade.

Uma, a primeira me fez passar por doido; outra, a segunda, me fez passar por néscio! Doido ou néscio, não escolho, porque a conseqüência é a mesma[...]. Portanto, querem condenar-me à miopia perpétua, miopia que para mim, é a cegueira, é a morte no seio da vida!... (apud PECHMAN, 2002, p. 194).

Estamos em 1869 e Macedo, uma espécie de moralista de sua época, parece querer ensinar a seus leitores a "ler" a realidade. A realidade de uma cidade que se tornara a capital do país e que a cada dia se transformava e se tornava mais complexa, exigindo novas chaves de leitura de seu cotidiano. O próprio Macedo já diagnosticara, em 1851, que

Uma nação não tem nada em si de mais cambiante e de menos nacional do que sua capital... pode ser que as mais importantes cenas desse drama (as contradições culturais e políticas da capital), que os episódios mais notáveis dessa vida, tenham por teatro, principalmente, as cidades..." (apud PECHMAN, 2002, pp. 190,191). 
O tema central do romance de Macedo é a questão do olhar como forma de conhecimento, coisa que projeta-nos diretamente na nova experiência urbana, onde, segundo Benjamin, é preciso se iniciar nos "princípios da arte de observar". Olhar, entender, formar juízo, decifrar é, por conseguinte, a chave de entrada na vida urbana moderna (PECHMAN, 2002, pp.196, 197). Ensinando o bom senso, que é a distância entre o bem e o mal absolutos, Macedo vai desbravando os enigmas da cidade para os leitores e, com isso, construindo dela a imagem da concórdia, lugar de articulação de um pacto urbano possível.

Não só Macedo com seu Simplício ensinava ler a cidade, mas também Manoel Antônio de Almeida com as malandragens de seu sargento de milícias; José de Alencar com seu Garatuja, que vivia rabiscando as paredes da cidade com caricaturas que zombavam das autoridades; Luis Guimarães Junior, com seu folhetim A família Agulha, que faz dos acontecimentos urbanos a urdidura de uma crônica cômica, gaiata e caricatural, todos, e outros muitos mais, lendo o Rio de Janeiro e fazendo dessa leitura uma estratégia estetizante para compreensão do próprio sentido da urbanidade.

Analisando o conto de Rubem Fonseca $A$ arte de andar nas ruas do Rio de Janeiro, como componente do enorme repertório de leituras dessa cidade, que atravessa todo o século XX e se estende para o século seguinte, Ana Cristina Viegas, em seu livro Literatura e consumo: o caso Rubem Fonseca, considera que o espaço da rua é o símbolo fundamental da vida moderna e, por isso mesmo, este lugar tem sido escrito e reescrito em diversos textos de diferentes autores. Desse conjunto de narrativas, assinala a autora, faz parte uma tradição de escritos sobre a cidade do Rio de Janeiro. Tradição a que se somam ilustradores e caricaturistas, outro grupo de leitores da cidade.

Exercitando-se em diferentes gêneros literários - contos, romances e, principalmente, crônicas -, vários escritores como Joaquim Manuel de Macedo, José de Alencar, Machado de Assis, Lima Barreto, João do Rio e tantos outros, percorreram as ruas do centro, construindo diversas interpretações. O texto de Rubem Fonseca insere-se em toda essa tradição e com ela dialoga (VIEGAS, 2002, p. 42).

Você sabe ler? Você sabe decifrar? Essas são as perguntas fundamentais que Rubem Fonseca faz, insistentemente, ao longo de toda sua extensa obra. Perguntas feitas a prostitutas, a mendigos, a matadores, a cobradores, a advogados, a polícia, aos escritores e aos... leitores. Repito: Você sabe ler... a cidade? Você sabe conviver na cidade? "A cidade não é aquilo que se vê do Pão-de-Açúcar", assinala o personagem do conto $O$ caso F.A. (FONSECA, 1994, p. 270). 
Fonseca não se interessa exatamente pela cidade mineral feita de concreto, aço e vidro que se estende, enorme e prepotente, diante de nossos olhos. Mal se vê a cidade de Fonseca e o autor parece apostar naquilo da cidade que não se dá a ver, na busca de um "quantum" de urbanidade que cada um possa ter como repertório pessoal no convívio coletivo. Não espanta, então, que seu personagem Augusto (de $A$ arte de andar...) queira escrever um livro sobre a arte de andar pelas ruas do Rio, mas que está longe de ser "um guia de turismo para viajantes em busca do exótico, do prazer, do místico, do horror, do crime e da miséria, como é do interesse de muitos cidadãos de recursos, estrangeiros, principalmente" (FONSECA, 1994, p.600). A arte de andar pelas ruas como uma espécie de guia de conhecimento da cidade, a partir da leitura de sua geografia e de sua história que, na esteira de João do Rio de A alma encantadora das ruas, pretende recuperar a esperança de comunhão com a cidade, na medida da reconquista de sua alma. Assim como o Macedo de A luneta mágica que quer dotar seu personagem míope da capacidade de ler o mundo e poder dele fazer algum juízo, Rubem Fonseca (com sua personagem Kelly, uma prostituta analfabeta) quer ensiná-la a ler para se haver com a cidade e, quem sabe, poder cobrar os seus direitos de cidadã.

Desconfiando de qualquer retórica, Rubem Fonseca propõe uma escrita que possibilite a leitura como arma de defesa contra a cultura de massas que assola a cidade, contra a deterioração das relações humanas. Entende-se, pois, que o livro que Augusto está escrevendo, não será “um guia arquitetônico do Rio antigo ou compêndio de arquitetura urbana; Augusto quer encontrar uma arte e uma filosofia peripatéticas que o ajudem a estabelecer uma melhor comunhão com a cidade. Solvitur ambulando" (Id, ibid). Ensinar a cidade caminhando por ela, resolver os problemas, como na antiga pólis, enquanto se caminha pela cidade.

Espremidos entre a escrita e a leitura da cidade e atravessados pelas vicissitudes da vida urbana, os personagens fonsequianos experimentam a cidade na crueza de suas pequenas tragédias, dos "pequenos tudo" frente aos que tudo podem. No conto Labareda das trevas, do livro Romance negro, surpreendemos uma breve passagem dessas vicissitudes. Trata-se de um jovem escritor que aos 23 anos teria escrito a obra perfeita, coisa que espanta muito o narrador do conto: “Nela havia a tragédia pura, não como nos gregos, um capricho dos deuses, mas como uma criação exclusiva dos homens. Ali estava tudo o que me interessava: o fracasso, o medo, a solidão, o desgosto, a corrupção, a covardia, o horror. O horror" (FONSECA, 1992, p. 54). 
A cidade de Fonseca está, portanto, verdadeiramente, nos afetos do encontro e do desencontro, nas complexidades da sociabilidade: “Somos continuadores da tragédia grega" dirá um personagem de Romance negro. O encontro com o Outro, a insuportabilidade do Outro ou a paixão pelo Outro atira-nos no coração do drama citadino. É o estranho que nos lembra as regras da convivialidade; ele constitui-se em regulador do que seria considerado agir de modo apropriado, dirão Sampaio e Rossi no artigo A condição de estranho nas relações cotidianas (SAMPAIO; ROSSI, 1999, p. 33). E concluem que o "outro" é fundamental na construção do "eu": "Nesse sentido a realidade das coisas é assegurada pelo compartilhar significados com o outro" (Idem, p. 39).

Veja-se o conto O outro, de 1975, que revela o embate entre um alto executivo e um pedinte de rua que o chantageia. O tremendo mal-estar produzido pelo pedinte acabará fazendo com que o pacífico e trabalhador executivo, o assassine.

Fonseca dialoga com a tragédia em busca de alguma transcendência, para sempre perdida, no cotidiano das grandes cidades, onde a figura do herói não é mais possível, diante da crise contemporânea dos valores. Os personagens vivem numa sociedade em que ao eclipse da ordem do transcendente seguiu-se o eclipse da crença na razão (FIGUEIREDO, 2003).

Sem Deus e sem Razão, o que será das cidades, se indaga Rubem Fonseca, sobre a ausência de qualquer referência a pautar o destino dos pobres viventes urbanos. Se a cidade se encolhe diante da banalidade do cotidiano, se o próprio sentido da ordem urbana se perde, se o conflito deixa de ser público, se despolitiza e passa a se limitar à esfera doméstica, como equacionar a condição humana, agora não mais dos semi-deuses gregos, mas de simples mortais, "pequenas criaturas" com suas pequenas tragédias pessoais? No limite, dirá Vera F. Figueiredo no seu livro Os crimes do texto: Rubem Fonseca e a ficção contemporânea, tal equacionamento se dará diante da condição urbana da cidade, que empurra os pequenos tudo para o desespero da sobrevivência. Na selva da cidade a condição urbana impõe à condição humana escolhas nem sempre éticas, mas fundamentais à sobrevivência do indivíduo.

Mas deixemos que Fonseca nos mostre isso e nos revele como a condição urbana se torna fator determinante na constituição da condição humana de seus personagens. Dito de outra maneira, a condição urbana é manifesta na obra de Fonseca a partir da "promessa de cidade", que se traduz na esperança de uma convivialidade possível, de proteção, de reconhecimento e de pertencimento. Tal promessa permeia o imaginário de 
gozos, confortos e ideais de ascensão pessoal sonhados pelos personagens, coisa já presente no seu segundo livro de contos, A coleira do cão, de 1965, no conto A força humana. A cena se passa numa academia de halterofilismo, onde o dono prepara os atletas para disputarem o concurso de melhor físico do ano. Conversando com um dos atletas o dono-treinador lhe afirma: "Posso fazer você famoso, você quer ficar famoso?" Ao que um dos alunos responde, "Pra quê?". Diante da inesperada resposta o treinador tenta explicar: “Em primeiro lugar pra não andar esfarrapado como um mendigo, e tomar banho quando quiser e comer - peru, morango, você já comeu morango? -, e ter um lugar confortável para morar, e ter mulher, não uma nega fedorenta, uma loura, muitas mulheres andando atrás de você, brigando para ter você, entendeu? Vocês nem sabem o que é isso, vocês são uns bundas-sujas mesmo" (FONSECA, 1994, p. 88). A condição urbana, que podemos chamar também de desejo de cidade, tão presente também no conto $A$ arte de andar nas ruas do Rio de Janeiro, de 1992, do livro Romance negro, funda a possibilidade da condição humana e o desejo de cidade se incorpora ao desejo na cidade.

No entanto, pouco se vê na obra de Fonseca a materialidade da condição urbana de vida. Não será, certamente, pelos prédios, lojas, viadutos ou pela concretude de cimento e aço, mas porque a vida é disputada na carne viva do dia-a-dia, na sobrevivência, na viração. A cidade, para Fonseca, está nos homens e não nas coisas. Beirando o cotidiano e penetrando no universo do homem comum ou da alta burguesia, Rubem Fonseca vai dali, extrair a essência da vida urbana, seja do alto executivo do conto Passeio noturno, que, para relaxar do estresse do trabalho, sai de noite com seu carrão para atropelar transeuntes no subúrbio; seja do batedor de carteira do conto Manhã de sol, que é pego em flagrante e faz de tudo para não ser fichado na delegacia. Aonde estará a verdade do homem urbano, no punguista que rouba para sustentar sete filhos ou no burguês com a barriga estufada de caviar e champanhe e que vê a vida como um banquete para uns poucos convidados? Não estranha, portanto, o travo amargo e peremptório de um cotidiano que faz com que os personagens passem a reger suas vidas por leis particulares e não mais pelas "leis da cidade" (FIGUEIREDO, 2003, p. 20). É emblemático nesse sentido o já citado conto $O$ outro, onde o assediado empresário em vez de recorrer à polícia resolve por conta própria seu problema, assassinando o impertinente pedinte.

A imposição das leis particulares às leis da cidade é o primeiro passo na constituição do que podemos chamar de cidade perversa, onde as leis da natureza, e 
mesmo o funcionamento pulsional, serão privilegiados ao funcionamento simbólico (DUFOUR, 2009, p. 278).

Segundo o sociólogo Robert Castel, até pelo menos os anos 70 pode-se considerar que a cidade foi o ponto de convergência de estratégias coletivas e individuais, onde a multiplicidade de interesses e desejos ainda encontravam sua expressão e acolhimento no exercício das lutas políticas, no exercício das liberdades e na luta pela criação de direitos e responsabilidades. O esvaziamento do poder urbano da cidade só se daria pela posterior precarização do pertencimento ao coletivo, que abriria caminho para o processo de reindividualização, com forte impacto sobre a capacidade do indivíduo de ressimbolizar o social. Impõe-se, então, um novo modo de socialização em que se sublinha a individualização, que tem como contrapartida o progresso do informal (CASTEL e HAROCHE, 2001, p.108). Essa nova socialidade coloca em jogo formas alternativas de percepção da sociedade, desdobrando-se daí uma sociedade em que as regras são pouco nítidas e na qual o limite entre o público e o privado é indefinido. A "adesão a si" é a marca dessa sociedade. É um declínio surpreendente da dimensão pública da sociedade. Para Castel,

o indivíduo com excesso de subjetividade, um indivíduo em que o excesso de investimento em si mesmo o desprendeu do social, está além da transgressão e da culpabilidade, como se ele tivesse dissolvido o mundo e o tivesse recoberto com as exigências de seu egotismo num subjetivismo sem limites (Idem, pp. 100, 133).

A literatura de Rubem Fonseca, com seus personagens superindividualistas, apartados da vida coletiva, aderidos unicamente às próprias causas, acompanha o processo de contaminação da cidade clássica - a cidade que obedece às leis criadas pelos homens para escapar às leis da natureza - pela cidade perversa, onde a passagem ao

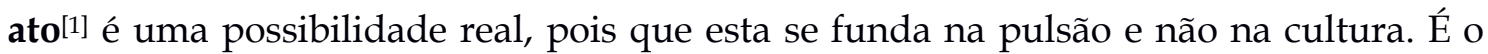
caso do conto $O$ cobrador, que é exemplar da condição de anomia na cidade, coisa que favorece a irrupção do imediatismo e da violência.

A rua cheia de gente, dentro de minha cabeça, e às vezes para fora, está todo mundo me devendo! Estão me devendo comida, buceta, cobertor, sapato, casa, automóvel, relógio, dentes, estão me devendo... Eu sou uma hecatombe/ Não foi nem Deus nem o Diabo/ Que me fez um vingador/Fui eu mesmo? Eu sou o Homem-Pênis/ Eu sou o Cobrador... Quando satisfaço meu ódio sou possuído por uma sensação de vitória, de euforia, que me dá vontade de dançar... Tenho uma missão... Sei que se todo fodido fizesse como eu o mundo seria melhor e mais justo... Já não perco meu tempo com sonhos... (FONSECA, 1994, pp. $492,499,500,503,504)$. 


\section{“A CIDADE NÃO É AQUILO QUE SE VÊ DO PÃO DE AÇÚCAR":}

NARRATIVAS URBANAS EM RUBEM FONSECA

A cidade vai deixando de ser a expressão de um pacto urbano e experimenta um processo de desinstitucionalização, de desengajamento, de desvinculamento e de descivilização. Em uma palavra, é a falência da esfera pública (PECHMAN, 2014).

O olhar atento de Rubem Fonseca sobre a cidade, na medida em que a esfera pública encolhe cada vez mais, faz da urbe objeto de sua escrita em contos que mais parecem instantâneos fotográficos da paisagem urbana e humana, onde nada do que é urbano, nada que é humano lhe é estranho.

Escrevendo sobre "pessoas empilhadas na cidade enquanto os tecnocratas afiam o arame farpado", como no conto Intestino grosso, Fonseca confirma que é na cidade que o ovo da serpente está sendo chocado:

Eu nada tenho a ver com Guimarães Rosa... passamos anos e anos preocupados com o que alguns cientistas cretinos ingleses e alemães... disseram sobre a impossibilidade de se criar uma civilização abaixo do Equador e decidimos arregaçar as mangas, acabar com os papos de botequim e, partindo de nossas lanchonetes de acrílico, fazer uma civilização como eles queriam, e construímos São Paulo, Santo André, São Bernardo e São Caetano, as nossas Manchesteres tropicais, com suas sementes mortíferas. Até ontem o símbolo da Federação das Indústrias do Estado de São Paulo eram três chaminés soltando grossos rolos negros de fumaça no ar... Não dá mais para Diadorim.

Fonseca tem experimentado em sua obra mostrar o endurecimento da cidade causado pela perda de comunicabilidade entre os seres humanos e o impacto disso na estruturação de novas formas de subjetividade. No conto Ganhar o jogo, do livro Pequenas criaturas, o narrador confirmará essa dureza da cidade: “Um sujeito como eu, branco, miserável, magro e famélico não tem irmãos nem aliados".

No autor, a perda da comunhão entre os homens e a cidade e, consequentemente, entre os próprios homens, leva à sua condenação à solidão, ao isolamento, à amargura, ao desafeto e à desconfiança. Se repararmos no movimento do autor, de livro para livro, notaremos que os personagens são arrancados, a cada obra, da intimidade familiar, da convivialidade grupal e lançados na amplidão do mundo, na cidade imprevisível. A partir daí a sua escrita desenha um percurso rumo à constituição de uma temática cujo fio condutor é o frágil equilíbrio entre a subjetividade e a objetividade das relações sociais, entre a casa e a rua, entre o privado e o público, entre a ternura e a violência, entre o acolhimento e o desprezo (PECHMAN; KUSTER, 2014).

Sabedor da inexistência de uma verdade final, Fonseca não ignora que as categorias do verdadeiro e do falso, do bem e do mal se tornaram obsoletas (FIGUEIREDO, 2003) e não será sem motivo que ele lança mão de um certo hiper- 
realismo para nos dar a exata medida do tamanho do drama que o viver na cidade impõe: "madureira flecha luz mão na bolsa dinheiro na mão. Dinheiro no bolso, três passos. Ladrão! Ladrão! Socorro! A mulher se agarra em madureira. Rua São Clemente. Dois PM correm - jogar dinheiro fora - braços presos pela mulher - PM" (FONSECA, 2004, p. 355).

Para Vera Follain o hiper-realismo,

teria sido motivado pela necessidade de explorar e reconstruir o mundo. Ao caos dos tempos presentes os hiper-realistas opõem o propósito de conhecer a situação atual, pela reconstituição da realidade objetiva, pela tentativa de atingir a "essência" dessa realidade (FIGUEIREDO, 2003, p.33).

Tentar arribar à verdade pelo excesso de realidade, mas como fazê-lo se o próprio Rubem não acredita numa verdade final? O Bem e o Mal não estando na essência das coisas, a linguagem ocupa o vazio deixado por uma verdade final inexistente (Idem, p. 19). É de ficção, de linguagem, pois, que se trata, melhor dizendo, de nomeação do mundo, das coisas desse mundo, de dar nome e, consequentemente, sentido ao que o homem faz no mundo, ao que faz nas cidades em que habita:

Faço a anatomia da realidade para mostrá-la ou entendê-la, negá-la, ou melhor ainda, para entender o que a realidade está fazendo com todos nós... o escritor não pode prescindir da sua imaginação, da capacidade de criar, inventar o que não viu, não ouviu, não tocou, não cheirou, não sentiu jamais. (FONSECA, 1997, p. 78).

Tudo em Fonseca trescala ao embate entre realidade e verdade: as epígrafes de seus contos, os títulos de seus livros, seus personagens, suas histórias, as cidades sob cujas sombras seus personagens se municiam com amor ou com o rancor do mundo. $\mathrm{O}$ paroxismo entre realidade e verdade atravessa toda a obra do autor. Veja-se o personagem Mandrake que reaparece no último livro de contos Calibre 22, de 2017. Personagem useiro e vezeiro da literatura fonsequiana, Mandrake é um detetive inspirado nos antigos gibis onde, com suas mágicas, com seu ilusionismo, faz crer que o que parece real seja verdadeiro e assim fazendo, recompõe uma realidade distorcida. Fonseca, num gesto mandrakiano, explora o impasse entre os dois termos porque a eles subjaz a esperança da recuperação da confiança no convívio, de uma realidade que seja verdadeira. Melhor dizendo, a vida de convívio só é possível quando confiamos no outro. Lidar com os outros sobre os quais não se possui informação total, configura resultados contingentes e confianças problemáticas. A confiança é questionável em 
situações de indeterminação comportamental e em momentos de fuga à visibilidade total. Entendamos confiança, no entanto, não como um simples gesto de boa-vontade, mas como uma relação social e a base para o desenvolvimento de relações sociais. Seja na opacidade da sociedade, seja na complexidade das interações sociais, seja na falta de visibilidade total com que a cidade se apresenta, a confiança é fundamental. Ela é fundamental também nas relações de corte urbano, pois são relações pautadas pela dúvida, incerteza e ignorância relativamente ao interlocutor, mas com assunção de elementos de encontro que possibilitam a própria relação social (FERREIRA, 2012).

Tal equação encontra clareza no conto O presente de Natal, de Calibre 22. Neste conto uma mulher vai visitar uma mãe de santo numa favela, e esta lhe revela que seu marido está possuído pelo demônio, a mesma coisa que a cartomante que fora consultar anteriormente lhe disse. Certa desta verdade, passou a acreditar que seu marido iria cortar seu pescoço justamente no dia 25 de dezembro.

O casal tinha vários convites para o dia de Natal, mas ambos decidiram passar em casa juntos, apenas os dois. Enquanto ceavam a mulher notou que o marido tinha um ar misterioso, "ele supõe que eu não sei o que vai fazer", pensou, enquanto acariciava a faca que tinha em mão.

"Tenho um presente para você", disse o marido, "fecha os olhos". Quando o marido se aproximou, ela enfiou a faca em seu peito. Ele caiu no chão. O colar que o marido tinha na mão ao bater no assoalho se rompeu e as pérolas pularam, tilintando ao lado do morto.

Se supormos que a confiança é o que dá suporte ao convívio social, entenderemos, por conseguinte, que a cidade não é possível na desconfiança. A partir do flexionamento da realidade com a verdade podemos analisar as diferentes camadas da obra de Fonseca.

Tome-se ao acaso algumas epígrafes que anunciam seus contos ou romances. Em Os prisioneiros lemos que "Somos prisioneiros de nós mesmos. Nunca se esqueça disso, e de que não há fuga possível", e em A coleira do cão que "Já quebrei meus grilhões, dirás talvez. Também o cão, com grande esforço, arranca-se da cadeia e foge. Mas, preso à coleira, vai arrastando um bom pedaço da corrente. Em Histórias de amor lemos: “Há o amor, é claro. E há a vida, sua inimiga". Aquilo que se anuncia como realidade nem sempre é verdade, aquilo que parece verdadeiro nem sempre se explica a partir de uma mesma realidade. Ou seja, tudo 
depende do valor atribuído às formas de comportamento de uma determinada cultura em um determinado momento, já que qualquer tentativa de imprimir um sentido único aos fatos resulta em fracasso... [Por isso mesmo], os personagens de Rubem Fonseca são indivíduos que se deparam, a todo instante, com essa ausência de fundamentos e de critérios que lhes permitam julgar-se e julgar o que se passa a seu redor... (FIGUEIREDO, 2003, pp. 19,20).

Títulos como Calibre 22, Axilas e outras histórias indecorosas, Amálgama, E do meio do mundo prostituto só amores guardei ao meu charuto, Pequenas criaturas, A coleira do cão, Os prisioneiros, Lúcia MacCartney, O cobrador, Feliz ano novo, dão abrigo a um mundo fabuloso, não no sentido de admirável, nem grandioso, mas no sentido alegórico, mitológico, relativo à lenda, a "uma história curta de onde se tira uma lição ou preceito moral" (FONSECA, 2013, p. 133). É, de alguma maneira, fabulando - relativizando entre a verdade e a realidade - que Rubem Fonseca organiza seu mundo, tentando entender, qual seria a lição, qual seria o preceito moral da fábula. No caso, Fonseca se apropria da fábula de Esopo, A cigarra e a formiga, para indagar:

(...) cantar é um crime que merece ser punido? (...) a alegria é um mal a ser combatido? (...) o desejo e o amor devem ser execrados? Todo animal, de certa forma, tem uma atividade predatória, claro que ninguém chega a ser tão destruidor quanto o ser humano. Mas entre a cigarra e a formiga, quem é o pior? Algumas poucas cigarras, cujas ninfas, ao se alimentarem da seiva das plantas, causam danos à arvore, ou milhões de formigas, que, organizadas em verdadeiros exércitos apocalípticos, escondidas em buracos, saem de maneira sorrateira sem nenhum tipo de desejo ou amor a não ser roubar furtivamente plantações inteiras para estocar em seus subterrâneos?

As fábulas de Esopo são uma lição de astúcia, de inteligência, de sagacidade, uma lição de moral?

Podem jogar essa merda no lixo. O meu exemplar já joguei (Idem, pp.134, 135).

Na fabulação de Fonseca não se trata apenas de ponderar entre a utilidade do trabalho, a poupança para a adversidade e a boemia da vida dos sentidos e dos prazeres do mundo. Fonseca não quer um mundo, não quer cidades econômicas que produzam homens estressados, preocupados com o rame-rame do cotidiano cinzento do trabalho e da rotina. Fonseca quer mais da vida, quer mais do mundo, quer mais dos homens. Foda-se é o título do conto de seu livro Amálgama e que execra a banalidade da vida jogada no pequeno, na economia dos afetos:

Ontem eu perdi meu carro. Ele não estava no seguro. Fui no boteco, pedi um chope, ergui o copo, disse "foda-se" e tomei um gole. O chope estava uma delícia. 
Sei que tem gente que não vai acreditar nesta história que estou contando.

Foda-se (Idem, p.155).

\section{Nota de rodapé}

[1] Trata-se do primado da força diante do silêncio e da impossibilidade de sentido da palavra. É o colocar em cena algo que não pode ser enunciado nem rememorado (BIRMAN, 2009).

\section{Referências}

BIRMAN, Joel. Cadernos sobre o mal. Rio de Janeiro, Ed. Civilização brasileira, 1999.

CASTEl, Robert; HAROCHE, Claudine. Propriété privée, propriété sociale, propriété de soi: entretetiens sur la construction de l'individu moderne. Paris: Ed. Fayard, 2001.

DUFOUR, Dany-Robert. La cité perverse: liberalisme et pornographie. Paris: Ed. Denoel, 2009.

FERREIRA, José M. Carvalho (org.). Sociedade de confiança: a construção social da confiança em Portugal. Lisboa: Ed. Clássica, 2012.

FIGUEIREDO, Vera Follain de. Os crimes do texto: Rubem Fonseca e a ficção contemporânea. Belo Horizonte: Ed. UFMG 2003.

FONSECA, Rubem. Labareda das trevas. In: Romance negro. São Paulo: Ed. Cia. das Letras, 1992.

. O caso F.A. In: Contos reunidos. São Paulo: Ed. Cia. das Letras, 1994.

. A arte de andar nas ruas do Rio de Janeiro. In: Contos reunidos. São Paulo: Ed. Cia. das Letras, 1994.

. O outro. In: Contos reunidos. São Paulo: Ed. Cia. das Letras, 1994.

. A força humana. In: Contos reunidos. São Paulo: Ed. Cia. das Letras, 1994.

. Passeio noturno. In: Contos reunidos. São Paulo: Ed. Cia. das Letras, 1994.

. Manhã de sol. In: Contos reunidos. São Paulo: Ed. Cia. das Letras, 1994.

. O cobrador. In: Contos reunidos. São Paulo: Ed. Cia. das Letras, 1994.

. Intestino grosso. In: Contos reunidos. São Paulo: Ed. Cia. das Letras, 1994. 
. Ganhar o jogo. In: Pequenas criaturas. São Paulo: Ed. Cia. das Letras, 2002.

Fábula. In: Amálgama. São Paulo: Ed. Cia. das Letras, 2013.

. Foda-se. In: Amálgama. São Paulo: Ed. Cia. das Letras, 2013.

. Calibre 22. In: Calibre 22. São Paulo: Ed. Cia. das Letras, 2017.

O presente de natal. In: Calibre 22. São Paulo: Ed. Cia. das Letras, 2017.

E do meio do mundo prostituto só amores guardei ao meu charuto. São Paulo: Ed. Cia. das Letras, 1997.

MACEDO, Joaquim M. de. Costumes campestres do Brasil. Revista Guanabara, Rio de Janeiro, jul. 1851, tomo I, n.8.

. A luneta mágica. Rio de Janeiro: Ed. Ática, 1995.

PECHMAN, Robert Moses, Cidades estreitamente vigiadas. O detetive e o urbanista. Rio de Janeiro, Ed. Casa da Palavra, 2002.

Da ordem, da cidade, da literatura: Rubem Fonseca e seus personagens à beira do "ruim do mundo". In: PECHMAN, Robert; KUSTER, Eliana. O chamado da cidade: ensaios sobre a urbanidade. Belo Horizonte: Ed. UFMG, 2014.

Quando Hannah Arendt vai à cidade e encontra com Rubem Fonseca. Ou da cidade, da violência e da política. In: PECHMAN, Robert; KUSTER, Eliana. O chamado da cidade: ensaios sobre a urbanidade. Belo Horizonte: Ed. UFMG, 2014.

SAMPAIO, Lilian; SAMPAIO, Patrícia, A condição de estranho na vida cotidiana. In: MARTINS, José de S. (org.). Vergonha e decoro na vida cotidiana da metrópole. São Paulo: Ed. Hucitec, 1999.

VIEGAS, Ana Cristina. Literatura e consumo: o caso Rubem Fonseca. Rio de Janeiro: Ed. Ágora da Ilha, 2002.

Recebido em 08/07/2017

Aceito em 18/09/2017. 